Article

\title{
Melting Diagrams of Adefovir Dipivoxil and Dicarboxylic Acids: An Approach to Assess Cocrystal Compositions
}

\author{
Hyunseon An, Insil Choi and Il Won Kim * (10 \\ Department of Chemical Engineering, Soongsil University, Seoul 06978, Republic of Korea; \\ hs4558@soongsil.ac.kr (H.A.); cisq@nate.com (I.C.) \\ * Correspondence: iwkim@ssu.ac.kr; Tel.: +82-2-820-0614; Fax.: +82-2-812-5378
}

Received: 30 December 2018; Accepted: 30 January 2019; Published: 30 January 2019

check for updates

\begin{abstract}
Pharmaceutical cocrystallization is a useful method to regulate the physical properties of active pharmaceutical ingredients (APIs). Since the cocrystals may form in various API/coformer ratios, identification of the cocrystal composition is the critical first step of any further analysis. However, the composition identification is not always unambiguous if cocrystallization is performed in solid state with unsuccessful solution crystallization. Single melting point and some new X-ray diffraction peaks are necessary but not sufficient conditions. In the present study, the use of melting diagrams coupled with the X-ray diffraction data was tested to identify cocrystal compositions. Adefovir dipivoxil (AD) was used as a model API, and succinic acid (SUC), suberic acid (SUB), and glutaric acid (GLU) were coformers. Compositions of AD/SUC and AD/SUB had been previously identified as 2:1 and 1:1, but that of AD/GLU was not unambiguously identified because of the difficulty of solution crystallization. Melting diagrams were constructed with differential scanning calorimetry, and their interpretation was assisted by powder X-ray diffraction. The cocrystal formation was exhibited as new compositions with congruent melting in the phase diagrams. This method correctly indicated the previously known cocrystal compositions of AD/SUC and AD/SUB, and it successfully identified the AD/GLU cocrystal composition as 1:1. The current approach is a simple and useful method to assess the cocrystal compositions when the crystallization is only possible in solid state.
\end{abstract}

Keywords: pharmaceutical cocrystal; melting diagram; liquid assisted grinding; adefovir dipivoxil; dicarboxylic acid

\section{Introduction}

Pharmaceutical crystallization plays a critical role in solid dosage forms, because the physicochemical properties of the solid forms of active pharmaceutical ingredients (APIs) are intrinsically defined by the structures of the API crystals. Salt formation is perhaps the most well-known example, and polymorphs, solvates, hydrates, and cocrystals are the important variations of the solid forms [1,2].

Pharmaceutical cocrystallization is an emerging technology that involves strong intermolecular interactions (usually hydrogen bonding) between APIs and coformers [3-5]. The diverse possibilities of coformers have expanded the landscape of pharmaceutical crystallization in a new dimension. The utility of the cocrystal formation includes the improvements of solubility, stability, processability, and so on [6-9]. Some examples of pharmaceutical cocrystals commercially available on the market are Farxiga ${ }^{\mathrm{TM}}$, Suglat ${ }^{\mathrm{TM}}$, Steglatro ${ }^{\mathrm{TM}}$, and Entresto ${ }^{\mathrm{TM}}$, and the cases are expected to increase steadily $[10,11]$. Experimental screening methods for the viable pairs of APIs/coformers are diverse, and a single method does not consider the entire range of cocrystal possibilities. Solution crystallization 
with cooling or solvent evaporation is perhaps most in line with the traditional crystallization processes [12,13]. However, spray drying is sometimes effective to discover the cocrystals not easily found using the usual solution method [14]. Liquid-assisted grinding is another versatile method bypassing solution crystallization, and it requires a relatively small amount of samples $[3,15]$. In addition, melt screening with an API/coformer mixing zone can effectively cover the diverse range of API/coformer compositions, which is at least qualitatively equivalent to the binary phase diagram [16].

Ultimately, the nature of API-coformer interactions as well as structural conformations is necessary to completely understand the characteristics of cocrystals. The usual method for the full characterization is single crystal X-ray diffraction (XRD), where the growth of relatively large crystals is required. Unfortunately, the formation of suitable single crystals is often elusive, and cocrystal generation through solution crystallization is not always straightforward $[9,17,18]$. In these cases, an alternative route is the solid-state preparation of cocrystals followed by the analysis of high-quality powder XRD data assisted by the Rietveld method, Monte Carlo simulated annealing, and molecular dynamics [19-21]. For this, the first imperative step is the identification of the correct API-coformer composition. Incorrect API/coformer mixtures during solid-state preparation may generate cocrystals contaminated by excess starting materials (i.e., API or coformer), which would in turn make it impossible to acquire high quality powder X-ray data suitable for structural analysis. (Note that the usual quantitative analysis of the solution (e.g., nuclear magnetic resonance spectroscopy) cannot be applied for the stoichiometry determination without pure cocrystals, which requires the knowledge of the predetermined stoichiometry in the case of the solid-state preparation.).

In the present study, we attempted to determine the API/coformer compositions of cocrystals through the combination of melting diagrams and powder XRD data of the API/coformer mixtures [22]. Adefovir dipivoxil (AD) with dicarboxylic acids (Figure 1: succinic (SUC), glutaric (GLU), and suberic (SUB) acids), long studied in our research group, was employed [23-26], and the mixtures were prepared by liquid-assisted grinding. We note here that the compositions of the adefovir dipivoxil cocrystals with succinic acid or suberic acid as coformers were identified undoubtedly in our previous studies of single crystal XRD [23,24], whereas that with glutaric acid was not unambiguously determined because of the difficulty of growing crystals through solution crystallization. (We re-emphasize that such difficulty has been shared in some other API cocrystal systems $[9,17,18]$.) The evidence in our previous study with glutaric acid, a single melting point and some new XRD peaks [26], turned out to be necessary but not sufficient conditions to make clear conclusions about the cocrystal composition as is shown in the present study.
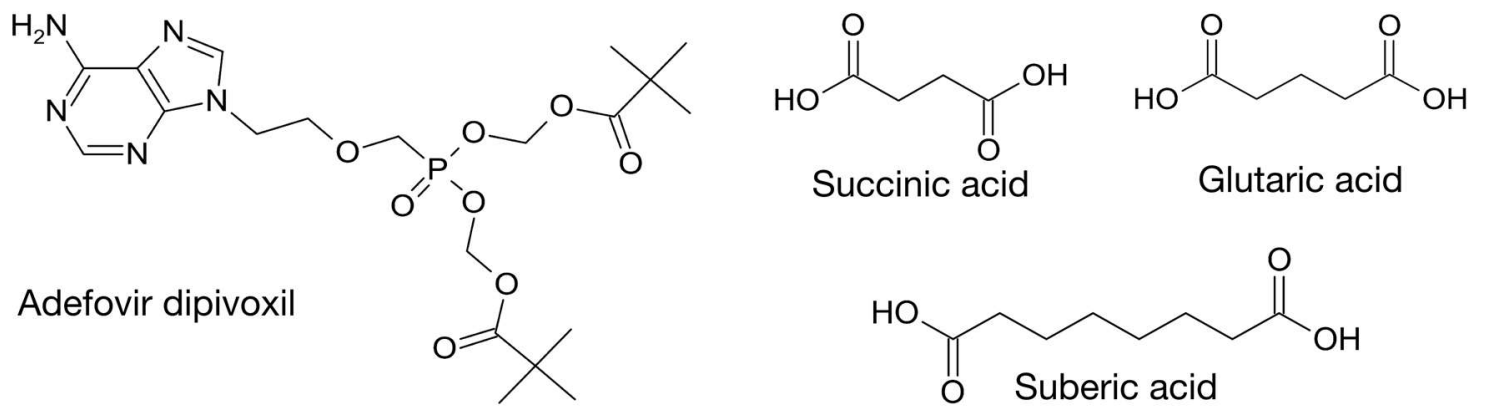

Figure 1. Chemical structures: adefovir dipivoxil (AD); succinic acid (SUC); glutaric acid (GLU); suberic acid (SUB).

\section{Materials and Methods}

\subsection{Cocrystallization}

Cocrystallization of adefovir dipivoxil (AD, form I: $\geq 98.0 \%$, Tokyo Chemical Industry Co., Tokyo, Japan; $\geq 99.68 \%$, Carbosynth, Berkshire, UK) and dicarboxylic acids was performed through 
liquid-assisted grinding at room temperature $\left(25-26^{\circ} \mathrm{C}\right)$ with an agate mortar and pestle. Dicarboxylic acids were succinic acid (SUC, $\geq 99.0 \%$ ), glutaric acid (GLU, 99\%), and suberic acid (SUB, 98\%), and they were all purchased from Sigma-Aldrich (Milwaukee, WI, USA). Chemical structures of the compounds are shown in Figure 1.

All experiments were at $0.2 \mathrm{mmol}$ (approximately $100 \mathrm{mg}$ ) AD scale, and various molar ratios of $\mathrm{AD} /$ dicarboxylic acid pairs were ground for $30 \mathrm{~min}$ with the addition of methanol (HPLC grade, J.T. Baker, Phillipsburg, NJ, USA) or ethanol (anhydrous 99.9\%, Samchun Chemical, Seoul, South Korea). For the AD/SUC mixture, $40 \mu \mathrm{L}$ ethanol was added every 5 min during grinding. For the AD/GLU mixture, $40 \mu \mathrm{L}$ methanol was added every $10 \mathrm{~min}$. For AD/SUB, $40 \mu \mathrm{L}$ methanol was added every $5 \mathrm{~min}$. After grinding, each product was moved to an open 4-mL glass vial to dry for $2 \mathrm{~h}$ at $35-45^{\circ} \mathrm{C}$ in a vacuum oven (J-DVO1, Jisico, Seoul, South Korea).

\subsection{Characterization}

Thermal properties of the ground $\mathrm{AD} /$ dicarboxylic acids were investigated in various molar ratios using a differential scanning calorimeter (DSC: DSC 812e, Mettler-Toledo, Columbus, OH, USA). DSC was pre-calibrated with indium for temperature and enthalpy. Temperature scan was from 25 to $200{ }^{\circ} \mathrm{C}$ with a scanning rate of $10{ }^{\circ} \mathrm{C} / \mathrm{min}$ under $\mathrm{N}_{2}(50 \mathrm{~mL} / \mathrm{min})$. A typical sample amount in an $\mathrm{Al}$ crucible ( $40 \mu \mathrm{L}$ volume with a top pinhole) was $2-4 \mathrm{mg}$. Melting points were measured at the onset temperatures of the first melting endotherms and at the peak temperatures of the final melting endotherms because the final endotherms were sometimes broad or overlapped.

Crystal phases were identified via X-ray diffraction (XRD: D2 PHASER, Bruker AXS, Billerica, MA, USA). The $2 \theta-\theta$ mode was employed to measure $2 \theta$ range $6-30^{\circ}\left(1^{\circ} / \mathrm{min}\right.$, increment $\left.0.02^{\circ}\right)$ with $\mathrm{CuK} \alpha$ radiation $(\lambda=1.5406 \AA$ ) at $30 \mathrm{kV}$ and $10 \mathrm{~mA}$. A Si low-background sample holder (Bruker AXS, Billerica, MA, USA) was used for increased sensitivity.

\section{Results and Discussion}

AD cocrystals with SUC and SUB were studied to evaluate the effectiveness of using the binary phase diagrams to assess the cocrystal compositions. The phase diagrams of AD/SUC and AD/SUB were constructed from the melting behavior of the powders, observed via DSC, which were obtained through liquid-assisted grinding. In addition, the crystal phases were identified using XRD.

The phase diagram of AD and SUC is shown in Figure 2a. Single melting behavior was observed at four different compositions: pure SUC $\left(\mathrm{x}_{\mathrm{AD}}=0\right.$, where $\mathrm{x}$ is mole fraction), $\mathrm{AD} / \mathrm{SUC}$ $=2: 3$ and 2:1, and pure $\mathrm{AD}\left(\mathrm{x}_{\mathrm{AD}}=1\right)$, in the order of increasing $\mathrm{AD}$ contents (Figures $2 \mathrm{a}, \mathrm{b}$ and $\mathrm{S} 1) . \mathrm{AD} / \mathrm{SUC}=2: 3\left(\mathrm{x}_{\mathrm{AD}}=0.4\right)$ was the eutectic composition formed of $\mathrm{SUC}\left(\mathrm{x}_{\mathrm{AD}}=0\right)$ and $\mathrm{AD} / \mathrm{SUC}$ $=2: 1\left(\mathrm{x}_{\mathrm{AD}} \cong 0.67\right)$. When $\mathrm{x}_{\mathrm{AD}}<0.4$, double melting behavior was observed: the eutectic melting and the melting of extra SUC of which the melting point was depressed proportional to the AD addition. When $\mathrm{x}_{\mathrm{AD}}>0.4$ in the $\mathrm{AD} / \mathrm{SUC}$ mixture, single melting was observed only at $\mathrm{AD} / \mathrm{SUC}=$ 2:1. Other compositions exhibited either eutectic melting or extra AD melting before reaching the other melting point, which was lower than the single melting point observed at AD/SUC $=2: 1$ (Figure 2). This indicates that the higher melting points when $\mathrm{x}_{\mathrm{AD}}>0.4$ are the depressed melting points of $\mathrm{AD} / \mathrm{SUC}$ cocrystals due to extra SUC $\left(0.4<\mathrm{x}_{\mathrm{AD}}<0.67\right)$ or extra $\mathrm{AD}\left(0.67<\mathrm{x}_{\mathrm{AD}}\right)$. The observation of the melting behavior at diverse compositions revealed that the cocrystal of $\mathrm{AD} / \mathrm{SUC}=2: 1$ formed during the liquid-assisted grinding (onset temperature $123^{\circ} \mathrm{C}$; heat of fusion $109 \mathrm{~J} / \mathrm{g}$ ).

XRD (Figures $2 \mathrm{c}$ and S2) also supported the conclusion made from the interpretation of the phase diagram. Representative XRD patterns are shown in Figure 2c. At AD/SUC = 2:1, new diffraction peaks appeared (e.g., $2 \theta=9.46,14.82$, and $23.93^{\circ}$, marked by star), which were absent in neat $\mathrm{AD}$ and SUC; characteristic AD (inverse triangle) and SUC (triangle) peaks disappeared as well, indicating complete conversion of $\mathrm{AD}$ and SUC into the new solid phase. At $\mathrm{AD} / \mathrm{SUC}=2: 3$, while the new diffraction peaks (star) showed up, residual SUC peak (triangle) remained, revealing that the extra SUC phase was present in addition to the new cocrystal phase. 

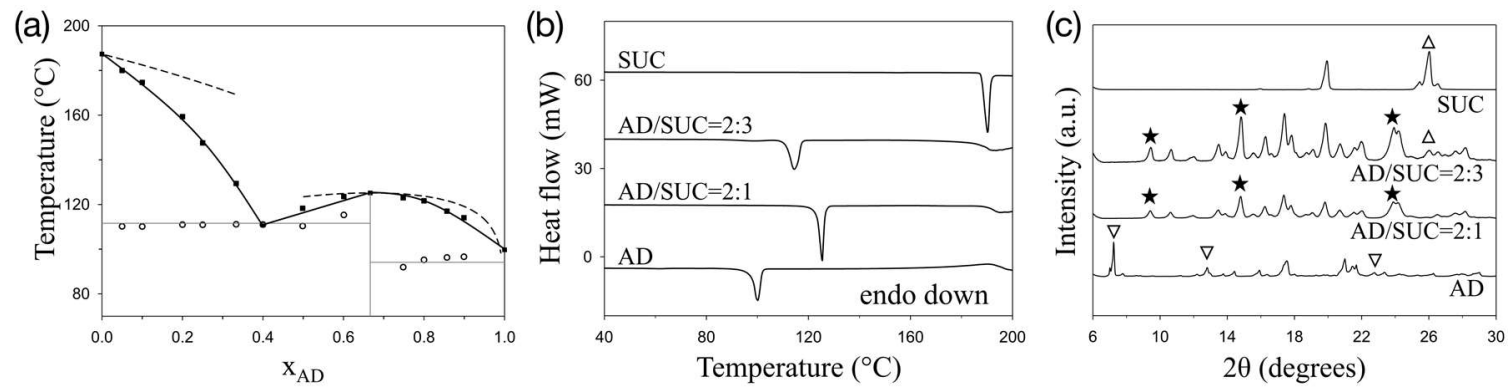

Figure 2. AD/SUC system: (a) melting diagram; (b) representative DSC thermograms; (c) representative XRD patterns. Top dashed lines in the melting diagram represent ideal liquidus lines. Some X-ray diffractions are marked as stars, triangles, and inverse triangles for cocrystal, SUC, and AD, respectively.

Overall, the aforementioned observations allowed us to conclude that the AD/SUC cocrystal composition was 2:1. This is in agreement with the previous single crystal XRD study, independently confirming the cocrystal composition [23]. We note that the liquid-assisted grinding of AD/SUC was performed with the addition of ethanol; methanol induced the polymorphism of the AD/SUC cocrystal, which significantly complicated the XRD and DSC analysis of the powder mixtures [25].

We also noted evidence suggesting partial miscibility between the AD/SUC cocrystal and SUC. The experimental heat of fusion at the eutectic composition of $\mathrm{AD} / \mathrm{SUC}=2: 3$ was $95 \mathrm{~J} / \mathrm{g}$, whereas the theoretical value was $146 \mathrm{~J} / \mathrm{g}$ based on the heat of fusion for neat cocrystal $(109 \mathrm{~J} / \mathrm{g})$ and SUC $(321 \mathrm{~J} / \mathrm{g})$ (Figure 2b). In addition, XRD peaks of the cocrystal at $21.54^{\circ}$ and $22.01^{\circ}$ displayed subtle changes (Figure S2). As the amount of extra SUC increased (from AD/SUC = 2:1 to 1:19), the $22.01^{\circ}$ peak was intensified and shifted to $21.86^{\circ}$, and the $21.54^{\circ}$ peak disappeared (no SUC diffraction peak exists in this diffraction region).

The AD/SUB system showed very similar behavior to the AD/SUC case, except that the eutectic and cocrystal formations were at different compositions. Single melting behavior was observed at four different compositions: pure $\mathrm{SUB}\left(\mathrm{x}_{\mathrm{AD}}=0\right), \mathrm{AD} / \mathrm{SUB}=1: 3$ and 1:1, and pure $\mathrm{AD}\left(\mathrm{x}_{\mathrm{AD}}=1\right)$, in the order of increasing AD contents (Figures 3a,b and S3). (Phase transformation of SUB itself at $131{ }^{\circ} \mathrm{C}$ was neglected for the purpose of diagram construction, and only the final melting was considered [27].) $\mathrm{AD} / \mathrm{SUB}=1: 3$ was the eutectic composition formed of $\mathrm{SUB}\left(\mathrm{x}_{\mathrm{AD}}=0\right)$ and $\mathrm{AD} / \mathrm{SUB}=1: 1\left(\mathrm{x}_{\mathrm{AD}}=0.5\right)$. When $\mathrm{x}_{\mathrm{AD}}<0.25$, double melting behavior was observed: the eutectic melting and the melting of extra SUB of which the melting point was depressed proportional to the AD addition. When $\mathrm{x}_{\mathrm{AD}}>0.25$ in the AD/SUB mixture, single melting was observed only at $\mathrm{AD} / \mathrm{SUB}=1: 1$. Other compositions exhibited either eutectic melting or extra $\mathrm{AD}$ melting before reaching the other melting point, which was lower than the single melting point observed at $\mathrm{AD} / \mathrm{SUB}=1: 1$ (Figure 3). This indicates that the higher melting points when $\mathrm{x}_{\mathrm{AD}}>0.25$ are the depressed melting points of $\mathrm{AD} / \mathrm{SUB}$ cocrystals due to extra SUB $\left(0.25<\mathrm{x}_{\mathrm{AD}}<0.5\right)$ or extra $\mathrm{AD}\left(0.5<\mathrm{x}_{\mathrm{AD}}\right)$. The observation of the melting behavior at diverse compositions revealed that the cocrystal of $\mathrm{AD} / \mathrm{SUB}=1: 1$ formed during the liquid-assisted grinding (onset temperature $131^{\circ} \mathrm{C}$; heat of fusion $148 \mathrm{~J} / \mathrm{g}$ ). We note that the liquid-assisted grinding of $\mathrm{AD} / \mathrm{SUB}$ was performed with the addition of methanol, and methanol solvate appeared with the excess $\mathrm{AD}\left(\mathrm{x}_{\mathrm{AD}}>0.5\right)$. The solvate-related data could be easily identifiable (melting point at around $79^{\circ} \mathrm{C}$ ) [28], and solvate domain in the phase diagram was omitted for simplification.

XRD (Figures $3 c$ and S4) also supported the interpretation of the phase diagram. Representative XRD patterns are shown in Figure 3c. At $A D / S U B=1: 1$, new diffraction peaks appeared (e.g., $2 \theta=7.01$, $9.07,18.54,19.51^{\circ}$, marked by star), which were absent in neat AD and SUB; characteristic AD (inverse triangle) and SUB (triangle) peaks disappeared as well, indicating complete conversion of AD and SUB into the new solid phase. At $\mathrm{AD} / \mathrm{SUB}=1: 3$, while the new diffraction peaks (star) showed up, residual SUB peak (triangle) remained, revealing that the extra SUB phase was present in addition to the new cocrystal phase. 

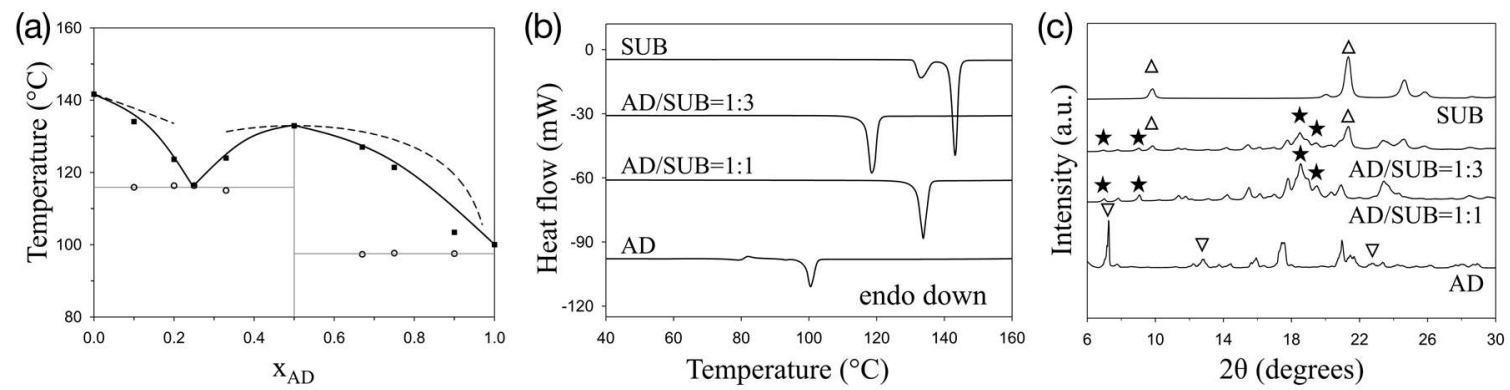

Figure 3. AD/SUB system: (a) melting diagram; (b) representative DSC thermograms; (c) representative XRD patterns. Top dashed lines in the melting diagram represent ideal liquidus lines. Some X-ray diffractions are marked as stars, triangles, and inverse triangles for cocrystal, SUB, and AD, respectively.

Overall, these observations allowed us to conclude that the AD/SUB cocrystal composition was 1:1. This is in agreement with the previous single crystal XRD study, independently confirming the cocrystal composition [24]. From the studies of AD/SUC and AD/SUB systems, the approach of constructing the phase diagram complemented by XRD analysis was hitherto proved successful for identifying the correct cocrystal compositions.

The AD/GLU system was investigated using the same approach, of which cocrystal composition had not been unambiguously determined because of the difficulty of cocrystal formation from solutions. Figure 4a shows the melting diagram of AD and GLU. Single melting behavior was observed at five different compositions: pure GLU $\left(\mathrm{x}_{\mathrm{AD}}=0\right), \mathrm{AD} / \mathrm{GLU}=1: 3,1: 1$, and 2:1, and pure $\mathrm{AD}\left(\mathrm{x}_{\mathrm{AD}}=1\right)$, in the order of increasing AD contents (Figures 4a,b and S5). (Phase transformation of GLU itself at $75{ }^{\circ} \mathrm{C}$ was neglected for the purpose of diagram construction, and only the final melting was considered [29].) $\mathrm{AD} / \mathrm{GLU}=1: 3$ was the eutectic composition formed of GLU $\left(\mathrm{x}_{\mathrm{AD}}=0\right)$ and $\mathrm{AD} / \mathrm{GLU}=1: 1\left(\mathrm{x}_{\mathrm{AD}}=0.5\right)$. Similarly, $\mathrm{AD} / \mathrm{GLU}=2: 1\left(\mathrm{x}_{\mathrm{AD}} \cong 0.67\right)$ was the eutectic composition formed of $\mathrm{AD} / \mathrm{GLU}=1: 1\left(\mathrm{x}_{\mathrm{AD}}\right.$ $=0.5)$ and $\mathrm{AD}\left(\mathrm{x}_{\mathrm{AD}}=1\right)$. The compositions around the eutectic points exhibited the eutectic melting as well as the depressed melting of the phases involved in the eutectic formation, namely, neat GLU, neat $\mathrm{AD}$, and $\mathrm{AD} / \mathrm{GLU}=1: 1$. The observation of the melting behavior at diverse compositions made us conclude that the cocrystal of $\mathrm{AD} / \mathrm{GLU}=1: 1$ formed during the liquid-assisted grinding (onset temperature $87^{\circ} \mathrm{C}$; heat of fusion $83 \mathrm{~J} / \mathrm{g}$ ).
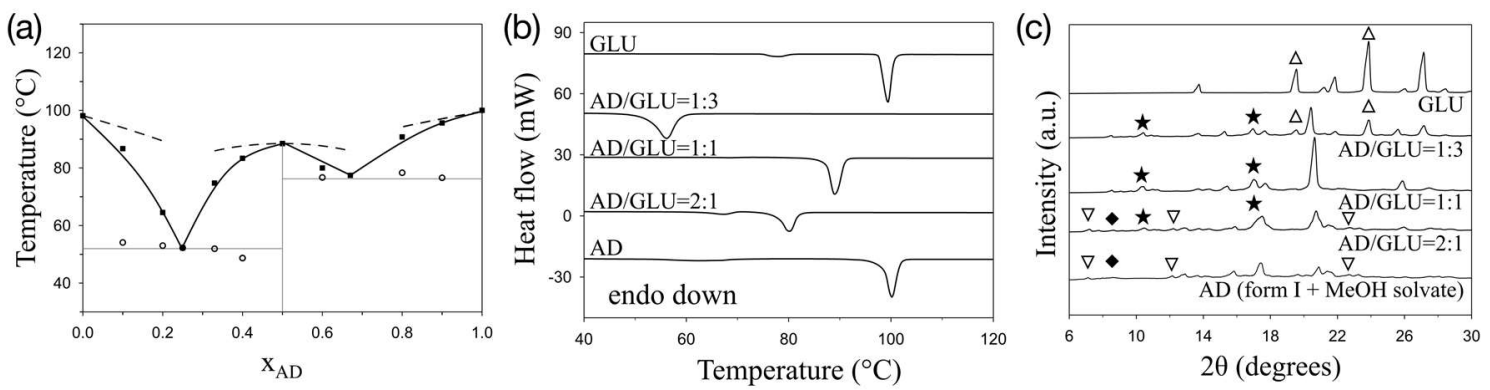

Figure 4. AD/GLU system: (a) melting diagram; (b) representative DSC thermograms; (c) representative XRD patterns. Top dashed lines in the melting diagram represent ideal liquidus lines. Some X-ray diffractions are marked as stars, triangles, inverse triangles, and diamonds for cocrystal, GLU, AD, and AD methanol solvate, respectively.

XRD (Figures 4c and S6) also supported the interpretation of the phase diagram. Representative XRD patterns are shown in Figure 4c. At $A D / G L U=1: 1$, new diffraction peaks appeared (e.g., $2 \theta=$ 10.42 and $17.67^{\circ}$, marked by star), which were absent in neat AD and GLU; characteristic AD (inverse triangle) and GLU (triangle) peaks disappeared as well, indicating complete conversion of AD and GLU into the new solid phase. At AD/GLU = 1:3, while the new diffraction peaks (star) showed up, residual GLU peaks (triangle) remained, implying that the extra GLU phase was present in addition to 
the new cocrystal phase. At AD/GLU = 2:1, while the new diffraction peaks (star) showed up, residual $\mathrm{AD}$ peaks (inverse triangle) remained, suggesting that the extra $\mathrm{AD}$ phase was present in addition to the new cocrystal phase.

Overall, the melting diagram approach assisted by XRD allowed us to conclude that the previously unknown composition of AD/GLU cocrystal was 1:1. We note that the liquid-assisted grinding of $\mathrm{AD} / \mathrm{GLU}$ was performed with the addition of methanol because of the too slow evaporation of ethanol during the grinding process, and the methanol solvate-related domain in the phase diagram (when $\mathrm{x}_{\mathrm{AD}}>0.5$ ) was omitted for clarity.

We also noted evidence suggesting partial miscibility between the AD/GLU cocrystal and GLU. An XRD peak of the cocrystal at $20.62^{\circ}$ displayed subtle changes when extra GLU existed (Figure $4 \mathrm{c}$ and Figure S6). This peak experienced a downward shift with extra GLU, and the shift was greatest to $20.42^{\circ}$ at the eutectic composition (AD/GLU $=1: 3$ ). Eutectic analysis based on the heat of fusion was unfortunately not possible. Since the eutectic temperature was below the phase transformation temperature of neat GLU, the theoretical heat of fusion during eutectic melting could not be calculated.

The emphasis of the current study was to find definite compositions with congruent melting using the phase diagrams, which were equivalent to the cocrystal compositions [30]. Further studies on the phase diagrams, for example, deviations from the ideal liquidus lines based on equilibrium theories (top dashed lines in Figures 2a, 3a, and 4a) and partial miscibility, may shed light on the formation mechanisms of the cocrystals and their compositional diversity [30,31].

\section{Conclusions}

Melting diagrams of AD and dicarboxylic acids were utilized to identify the compositions of $\mathrm{AD} /$ dicarboxylic acid cocrystals. DSC was employed for the observation of thermal behavior at different ratios of $\mathrm{AD} /$ coformer mixtures, and XRD was used to identify the solid phases of the powder mixtures. $\mathrm{AD} / \mathrm{SUC}=2: 1$ and $\mathrm{AD} / \mathrm{SUB}=1: 1$, which had been previously determined through single crystal XRD, were correctly identified through the current phase diagram approach. Moreover, the composition of AD/GLU cocrystal was newly identified as 1:1, which could not be previously specified due to the difficulty of solution crystal growth. The current approach can be summarized as finding new compositions with congruent melting in the melting diagrams. It will be useful for the cocrystals that cannot be easily grown using the solution method, since the identification of the cocrystal compositions is the critical first step toward the more quantitative structural analysis.

Supplementary Materials: The following are available online at http://www.mdpi.com/2073-4352/9/2/70/s1, Figure S1: DSC thermograms for the AD/SUC system, Figure S2: XRD patterns for the AD/SUC system, Figure S3: DSC thermograms for the AD/SUB system, Figure S4: XRD patterns for the AD/SUB system, Figure S5: DSC thermograms for the AD/GLU system, Figure S6: XRD patterns for the AD/GLU system.

Author Contributions: I.W.K and H.A. designed the experiments, analyzed the data, and wrote the paper; H.A. performed most of the experiments; I.C. helped H.A. with some of the experiments.

Acknowledgments: This research was supported by the Basic Science Research Program through the National Research Foundation of Korea (NRF) funded by the Ministry of Education (NRF- 2015R1D1A1A01058116).

Conflicts of Interest: The authors declare no conflict of interest. The funding sponsors had no role in the design of the study; in the collection, analyses, or interpretation of data; in the writing of the manuscript; and in the decision to publish the results.

\section{References}

1. Stahl, P.H.; Nakano, M. Pharmaceutical aspects of the drug salt form. In Handbook of Pharmaceutical Salts, 1st ed.; Stahl, P.H., Wermuth, C.G., Eds.; WILEY-VCH: Weinheim, Germany, 2008; pp. 83-116. ISBN 978-3-906390-58-1.

2. Rao, V.M.; Sanghvi, R.; Zhu, H. Solubility of pharmaceutical solids. In Developing Solid Oral Dosage Forms, 1st ed.; Qiu, Y., Chen, Y., Zhang, G.G.Z., Liu, L., Porter, W.R., Eds.; Academic Press: Burlington, MA, USA, 2009; pp. 1-24. ISBN 978-0-444-53242-8. 
3. Jones, W.; Motherwell, W.D.S.; Trask, A.V. Pharmaceutical cocrystals: An emerging approach to physical property enhancement. MRS Bull. 2006, 31, 875-879. [CrossRef]

4. Shan, N.; Zaworotko, M.J. The role of cocrystals in pharmaceutical science. Drug Discov. Today 2008, 13, 440-446. [CrossRef] [PubMed]

5. Rodríguez-Hornedo, N.; Nehm, S.J.; Jayasankar, A. Cocrytals: Design, properties and formation mechanisms. In Encyclopedia of Pharmaceutical Technology, 3rd ed.; Swarbrick, J., Ed.; Informa Healthcare: New York, NY, USA, 2007; Volume 1, pp. 615-635. ISBN 978-0-8493-9396-9.

6. Chow, S.F.; Chen, M.; Shi, L.; Chow, A.H.L.; Sun, C.C. Simultaneously improving the mechanical properties, dissolution performance, and hygroscopicity of ibuprofen and flurbiprofen by cocrystallization with nicotinamide. Pharm. Res. 2012, 29, 1854-1865. [CrossRef] [PubMed]

7. Good, D.J.; Rodríguez-Hornedo, N. Solubility advantage of pharmaceutical cocrystals. Cryst. Growth Des. 2009, 9, 2252-2264. [CrossRef]

8. Trask, A.V.; Motherwell, W.D.S.; Jones, W. Physical stability enhancement of theophylline via cocrystallization. Int. J. Pharm. 2006, 320, 114-123. [CrossRef] [PubMed]

9. Karki, S.; Friščić, T.; Fábián, L.; Laity, P.R.; Day, G.M.; Jones, W. Improving mechanical properties of crystalline solids by cocrystal formation: New compressible forms of paracetamol. Adv. Mat. 2009, 21, 3905-3909. [CrossRef]

10. Wood, P.A.; Feeder, N.; Furlow, M.; Galek, P.T.A.; Groom, C.R.; Pidcock, E. Knowledge-based approaches to co-crystal design. CrystEngComm 2014, 16, 5839-5848. [CrossRef]

11. Kumar, A.; Kumar, S.; Nanda, A. A review about regulatory status and recent patents of pharmaceutical co-crystals. Adv. Pharm. Bull. 2018, 8, 355-363. [CrossRef]

12. Yu, Z.Q.; Chow, P.S.; Tan, R.B.H. Operating regions in cooling cocrystallization of caffeine and glutaric acid in acetonitrile. Cryst. Growth Des. 2010, 10, 2382-2387. [CrossRef]

13. Zhang, S.; Chen, H.; Rasmuson, Å.C. Thermodynamics and crystallization of a theophylline-salicylic acid cocrystal. CrystEngComm 2015, 17, 4125-4135. [CrossRef]

14. Alhalaweh, A.; Kaialy, W.; Buckton, G.; Gill, H.; Nokhodchi, A.; Velaga, S.P. Theophylline cocrystals prepared by spray drying: Physicochemical properties and aerosolization performance. AAPS PharmSciTech 2013, 14, 265-276. [CrossRef] [PubMed]

15. Friščić, T.; Jones, W. Recent advances in understanding the mechanism of cocrystal formation via grinding. Cryst. Growth Des. 2009, 9, 1621-1637. [CrossRef]

16. Berry, D.J.; Seaton, C.C.; Clegg, W.; Harrington, R.W.; Coles, S.J.; Horton, P.N.; Hursthouse, M.B.; Storey, R.; Jones, W.; Friščić, T.; et al. Applying hot-stage microscopy to co-crystal screening: A study of nicotinamide with seven active pharmaceutical ingredients. Cryst. Growth Des. 2008, 8, 1697-1712. [CrossRef]

17. Shevchenko, A.; Bimbo, L.M.; Miroshnyk, I.; Haarala, J.; Jelínková, K.; Syrjänen, K.; van Veen, B.; Kiesvaara, J.; Santos, H.A.; Yliruusi, J. A new cocrystal and salts of itraconazole: Comparison of solid-state properties, stability and dissolution behavior. Int. J. Pharm. 2012, 436, 403-409. [CrossRef] [PubMed]

18. Karki, S.; Fábián, L.; Friščić, T.; Jones, W. Powder X-ray diffraction as an emerging method to structurally characterize organic solids. Org. Lett. 2007, 9, 3133-3136. [CrossRef] [PubMed]

19. Harris, K.D.M.; Tremayne, M.; Kariuki, B.M. Contemporary advances in the use of powder X-ray diffraction for structure determination. Angew. Chem. Int. Ed. 2001, 40, 1626-1651. [CrossRef]

20. Day, G.M.; van de Streek, J.; Bonnet, A.; Burley, J.C.; Jones, W.; Motherwell, W.D.S. Polymorphism of scyllo-inositol: Joining crystal structure prediction with experiment to elucidate the structures of two polymorphs. Cryst. Growth Des. 2006, 6, 2301-2307. [CrossRef]

21. Friščić, T.; Halasz, I.; Strobridge, F.C.; Dinnebier, R.E.; Stein, R.S.; Fábián, L.; Curfs, C. A rational approach to screen for hydrated forms of the pharmaceutical derivative magnesium naproxen using liquid-assisted grinding. CrystEngComm 2011, 13, 3125-3129. [CrossRef]

22. Évora, A.O.L.; Castro, R.A.E.; Maria, T.M.R.; Silva, M.R.; ter Horst, J.H.; Canotilho, J.; Eusébio, M.E.S. Co-crystals of diflunisal and isomeric pyridinecarboxamides-A thermodynamics and crystal engineering contribution. CrystEngComm 2016, 18, 4749-4759. [CrossRef]

23. Jung, S.; Ha, J.-M.; Kim, I.W. Bis[(2,2-dimethylpropanoyloxy)methyl]\{[2-(6-amino-9H-purin-9-yl)ethoxy] methyl\}phosphonate-succinic acid (2/1). Acta Crystallogr. E 2012, 68, o809-o810. [CrossRef] [PubMed]

24. Jung, S.; Lee, J.; Kim, I.W. Structures and physical properties of the cocrystals of adefovir dipivoxil with dicarboxylic acids. J. Cryst. Growth 2013, 373, 59-63. [CrossRef] 
25. Jung, S.; Ha, J.-M.; Kim, I.W. Phase transformation of adefovir dipivoxil/succinic acid cocrystals regulated by polymeric additives. Polymers 2014, 6,1-11. [CrossRef]

26. Jung, S.; Choi, I.; Kim, I.W. Liquid-assisted grinding to prepare a cocrystal of adefovir dipivoxil thermodynamically less stable than its neat phase. Crystals 2015, 5, 583-591. [CrossRef]

27. Roux, M.V.; Temprado, M.; Chickos, J.S. Vaporization, fusion and sublimation enthalpies of the dicarboxylic acids from C4 to C14 and C16. J. Chem. Thermodyn. 2005, 37, 941-953. [CrossRef]

28. Arimilli, M.N.; Kelly, D.E.; Lee, T.T.K.; Manes, L.V.; Munger, J.D., Jr.; Prisbe, E.J.; Schultze, L.M. Nucleotide Analog Compositions. U.S. Patent 6,451,340, 17 September 2002.

29. Dheep, G.R.; Sreekumar, A. Investigation on thermal reliability and corrosion characteristics of glutaric acid as an organic phase change material for solar thermal energy storage applications. Appl. Therm. Eng. 2018, 129, 1189-1196. [CrossRef]

30. Soustelle, M. Phase Transformations, 1st ed.; ISTE Ltd.: London, UK, 2015; pp. 75-112. ISBN 978-1-84821-868-0.

31. Prigogine, I.; Defay, R. Chemical Thermodynamics, 1st ed.; Longmans: London, UK, 1954; pp. 357-380. ISBN 978-0582462830.

(C) 2019 by the authors. Licensee MDPI, Basel, Switzerland. This article is an open access article distributed under the terms and conditions of the Creative Commons Attribution (CC BY) license (http://creativecommons.org/licenses/by/4.0/). 